\title{
Letters
}

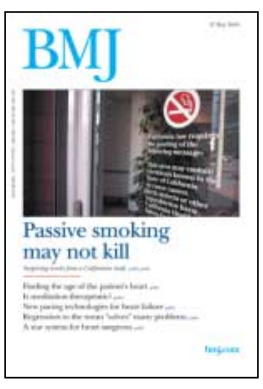

\section{Passive smoking}

\section{Study was flawed from outset}

EDITOR-The study by Enstrom and Kabat has a major flaw, ${ }^{1}$ and I urge the editors of the $B M J$ to consider a retraction. The study assumes a considerable difference in the exposure to environmental tobacco smoke of never smokers' spouses compared to ever smokers' spouses. This is obviously wrong.

Most never smokers' spouses would have been exposed to considerable environmental tobacco smoke before the late 1990s when Californian public places became smoke-free. Thus for most of the study period, assuming the spouses are together for two to four waking hours a day, the comparison is eight to10 hours' exposure to tobacco smoke among spouses of never smokers and 12 hours' exposure to tobacco smoke among spouses of ever smokers. Assuming passive smoking increases mortality by $30 \%$, the demonstrable difference between the groups would be about $5 \%$ $((12-10) / 12) \times 30)$. This would be further reduced because of quitters among ever smokers and occasional smokers among never smokers. A 5\% difference is extremely difficult to show in an epidemiological study, and inability to find a difference cannot be taken as absence of a difference.

However flawed this study, unless it is retracted by the $B M J$ the tobacco industry will use it to promote their vigorous opposition to antismoking legislation in general, and anti-environmental tobacco smoke laws in particular, creating controversy where there isn't any. Of course they have an urgent and ongoing need to replace loss of their customer base - 10 000-20 000 lives per daywith new recruits of young smokers.

Jayant Sharad Vaidya specialist registrar

Department of Surgery, Whittington and Middlesex Hospitals, University College London, London W1W 7EJ

j.vaidya@ucl.ac.uk

Competing interests: None declared.

1 Enstrom JE, Kabat, GC. Environmental tobacco smoke and tobacco related mortality in a prospective study of Californians, 1960-98. BMJ 2003;326:1057. (17 May.)

\section{Wider evidence needs to be interpreted}

EDITOR-Enstrom and Kabat's analysis has several omissions. ${ }^{1}$ First they accept that most epidemiological studies have found positive but not statistically significant relationships between environmental tobacco smoke, coronary heart disease, and lung cancer, but then argue against meta- analysis to establish a causal relation. This is precisely where systematic reviews, and sometimes meta-analysis, show considerable benefit by increasing power. Enstrom and Kabat say that publication bias may explain positive results in reviews; however, larger cohort studies, unlike small trials and reports, are more likely to be published, regardless of results. ${ }^{2}$ They do not explain heterogeneity between their findings and others, simply arguing that their cohort is large, and has more strengths. In fact, large prospective cohort studies like this may have greater losses to follow up, or more misclassification, over time. ${ }^{3}$

Misclassification, mentioned by the authors, may explain the apparent lack of association. Furthermore, the relative risks reported for active smoking and coronary heart disease (relative risk 1.5, table 10 in the paper) are lower than other cohort studies, which may be sufficient to obscure a modest but important increase in risk. $^{45}$ They further assume an (unlikely) linear relation between cigarette smoking and mortality to validate their main results (extrapolating a very low estimate of a relative risk of 1.03 for coronary heart disease, by implying that environmental tobacco smoke is equivalent to smoking one cigarette per day). This analysis is unclear and unconvincing.

One study is insufficient to overturn established relations between environmental tobacco smoke and mortality, and I think that the authors overemphasise their negative findings.

Julia Critchley lecturer

International Health Research Group, Liverpool School of Tropical Medicine, Liverpool L3 5QA juliac@liverpool.ac.uk

Competing interests: None declared.

1 Enstrom JE, Kabat, GC. Environmental tobacco smoke and tobacco related mortality in a prospective study of Californians, 1960-98. BMJ 2003;326:1057. (17 May)

2 Sutton AJ, Duval SJ, Tweedie RL, Abrams KR, Jones DR. Empirical assessment of effect of publication bias on meta-analysis. BMJ 2000;320:1574-7.

3 Critchley JA, Unal B. The health effects associated with smokeless tobacco use: a systematic review. Thorax 2003;58:435-43

4 National Center for Chronic Disease Prevention and Health Promotion. Tobacco Information and Prevention Source. Report of the Surgeon General. Women and smoking, 2001. www.cdc.gov/tobacco/sgrpage.htm\#2000s ing, 2001. www.cdc.
(accessed 14 Aug 2003).

5 Jousilahti P, Vartiainen E, Korhonen HJ, Puska P, Tuomile5 Jousilahti P, Vartiainen E, Korhonen HJ, Puska P, Tuomile-
hto J. Is the effect of smoking on the risk for coronary heart hto J. Is the effect of smoking on the risk for coronary heart
disease even stronger than was previously thought? J Cardisease Risk 1999;6:293-8.
Paper does not diminish conclusion of previous reports

EDITOR-I am writing on behalf of members of the 2002 working group on involuntary smoking and cancer for the International Agency for Research on Cancer (IARC). ${ }^{1}$ We concluded that environmental tobacco smoke causes lung cancer among never smokers. The paper by Enstrom and Kabat ${ }^{2}$ does not diminish this conclusion or those of previous reports. ${ }^{3-5}$

Enstrom and Kabat's paper was based on one of the 25 US states (California) in the American Cancer Society's prevention study. The relative risk of lung cancer in never smoking women married to ever smokers was reported as $0.99(95 \%$ confidence interval 0.72 to 1.37 ), based on only 177 cases, whereas the IARC meta-analysis, based on 46 studies and 6257 cases, yielded an estimate of 1.24 (95\% confidence interval 1.14 to 1.34). ${ }^{1}$ The estimate of Enstrom and Kabat is consistent with both an increased risk of lung cancer (the confidence interval includes the IARC estimate of 1.24) and no effect. Adding the result from Enstrom and Kabat to the IARC analysis reduces the pooled estimate to 1.23.

The observed relative risk of 0.99 is based on the smoking status of husbands in 1959 , but many would have quit by 1998 , particularly in California. Table 8 in the paper confirms this; in $195963 \%$ of ever smoking husbands were current smokers compared with $26 \%$ in 1998. This exposure misclassification would mask the association between exposure to environmental tobacco smoke and lung cancer.

IARC's classification of environmental tobacco smoke as a human carcinogen was based on the full scope of evidence; observational studies, carcinogenic components of environmental tobacco smoke, experimental models, and biomarker studies. Additionally, active smoking is an established cause of lung cancer, and knowledge of mechanisms of carcinogenesis implies no risk free level of exposure to tobacco smoke. Enstrom and Kabat's conclusions are not supported by the weak evidence they offer, and, although the accompanying editorial alluded to "debate" and "controversy," we judge the issue to be resolved scientifically, even though the "debate" is cynically continued by the tobacco industry.

Allan Hackshaw deputy director

Cancer Research UK and UCL Cancer Trial Centre, University College London, London NW1 2ND

allan.hackshaw@ctc.ucl.ac.uk

Competing interests: None declared. 
1 International Agency for the Research on Cancer (IARC) Monograph on Tobacco Smoke and Involuntary Smoking. Volume 83, Lyon (in press)

Volume 83, Lyon (in press). Enstrom JE, Kabat, GC. Environmental tobacco smoke and
tobacco related mortality in a prospective study of Califortobacco related mortality in a prospective stud
nians, 1960-98. BMJ 2003;326:1057. (17 May.)

nians, 1960-98. BMJ 2003;326:1057. (17 May.)
3 United States Department of Health and Human Services. United States Department of Health and Human Services The health consequences of involuntary smoking a report of the surgeom general. Washington, DC: US Government Printing
Office, 1986.

United States Environmental Protection Agency. Respiraory health effects of passive smoking: lung cancer and other disrders. Washington DC: Office of Research and Develop-

Report of the Scientific Committee on Tobacco and Health. London: Stationery Office, 1998.

Members of the IARC Working group: Patricia Buffler (USA), Richard Doll (UK), Elizabeth Fontham (USA), Yu-Tang Gao (China), Prakash Gupta (India), Allan Hackshaw (UK), Elena Matos (Argentina), Jonathon Samet (USA), Michael Thun (USA), Kurt Straif (France), Paolo Vineis (Italy), H-Erich Wichmann (Germany), Anna Wu (USA), David Zaridze (Russia).

\section{Inverse correlation of smoking and} education should have raised suspicion

EDITOR-It is well known that smoking is inversely correlated with education level; the highest percentage of smokers is found among those people who have not completed high school. This inverse correlation of smoking and education has been true for many years. It is referred to in the 15 th edition (1977-9) of the Encyclopedia Britannica. Clearly, this casts suspicion on the data entry and the programming used by Enstrom and Kabat to perform their analysis, ${ }^{1}$ because they find that the highest frequency of smoking is associated with the highest level of education.

From their table 2 (male never smokers) and table 3 (female never smokers) sorted by smoking status of spouse, they show that the heaviest smokers ( $\geq 40$ cigarettes/day) are more likely to have completed high school than are non-smokers. Further, among smokers, they show that for those smoking a higher number of cigarettes the likelihood of completing high school is greater.

Because the "never smoked/formerly smoked" group does not show the expected higher proportion of high school graduates, this implies that there were a sizeable number of smokers included among the non-smokers; that would account for the spouses of "non-smokers" not exhibiting a lower rate of heart disease.

John H Glaser independent researcher

4 Woodpark Circle, Lexington, MA 02421, USA glasej@alum.mit.edu

Competing interests: None declared.

1 Enstrom JE, Kabat, GC. Environmental tobacco smoke and tobacco related mortality in a prospective study of Californians, 1960-98. BMJ 2003;326:1057. (17 May.)

\section{Secondhand smoke does cause respiratory disease}

EDITOR-The report by Enstrom and Kabat confirms that exposure to secondhand smoke causes injury to the respiratory system with the finding of a combined increased mortality risk for men and women for chronic obstructive pulmonary disease (relative risk 1.65, 95\% confidence interval 1.0 to 2.73$){ }^{1}$ This is consistent with other investigations that show the sensitivity of the respiratory system to secondhand smoke at all ages and in different settings. In Hong Kong several studies have shown that the exposure of infants to secondhand smoke in utero or postnatally in the home was linked to higher consultation rates and hospitalisation for respiratory and other illnesses. ${ }^{2}$ Smoking in the home was clearly associated with bronchitic symptoms in a cohort of primary school children, independently of ambient air pollution. ${ }^{3}$ In an adult workforce, workplace exposures to passive smoking were associated with significant excess risks $(66 \%$ to $212 \%)$ for all respiratory symptoms and increased healthcare costs. ${ }^{4}$ In a population survey the prevalence of secondhand smoke exposures at work was $47.5 \%$ among non-smoking full time workers compared with only $26 \%$ at home. People exposed at work were $37 \%$ more likely to consult a doctor for respiratory illness. The increased healthcare costs for primary care alone among three million workers was estimated at US $\$ 29 \mathrm{~m}$ (£18m; €26m) annually. Four independent case control studies on lung cancer and passive smoking in Hong Kong, reviewed by the United States Environmental Protection Agency, gave an overall relative risk of 1.48 (1.21 to 1.81 ).

In other words, we have epidemics of respiratory disease in Hong Kong caused by secondhand smoke. However, because of the way in which the Enstrom and Kabat paper was presented little or no attention will be paid in media reports to the findings on mortality risks from respiratory disease.

A J Hedley professor in community medicine T H Lam professor

S M McGhee associate professor

G M Leung assistant professor

M Pow research assistant

Department of Community Medicine, University of Hong Kong, Hong Kong Special Administrative Region, China

commed@hkucc.hku.hk

Competing interests: $\mathrm{AJH}$ is a former chairman of the Hong Kong Council on Smoking and Health (COSH). THL is current vice chairman of COSH. All of the authors conduct research on the health effects of active and passive smoking and have received research funds, through their employer, the University of Hong Kong, to support their work.

1 Enstrom JE, Kabat, GC. Environmental tobacco smoke and tobacco related mortality in a prospective study of Californians, 1960-98. BMJ 2003;326:1057. (17 May.)

2 Lam TH, Leung GM, Ho LM. The effects of environmental tobacco smoke on health services utilization in the firs eighteen months of life. Pediatrics 2001;107:e91.

3 Peters J, Hedley AJ, Wong CM, Lam TH, Ong SG, Liu J, et al. Effects of an ambient air pollution intervention and . Lirects of ant tobace smoke on children's respiratory environmental tobacco smoke on children's respi
health in Hong Kong. Int J Epidemiol 1996;25:821-8.

4 McGhee SM, Adab P. Hedley AJ, Lam TH, Ho LM, Fielding R, et al. Passive smoking at work: the short term cost. J Epidemiol Community Health 2000;54:673-6.

5 McGhee SM, Hedley AJ, Ho LM. Passive smoking and its impact on employers and employees in Hong Kong. Occup Environ Med 2002;59:842-6.

\section{Doubts about effectiveness of age adjustment}

EDITOR-According to Enstrom and Kabat's figures the greater had been a man's cigarette consumption in 1959 the less likely, it seems, was the death of his wife from coronary heart disease. ${ }^{1}$ However, an age bias existed in those women at the outset. In 1959 their mean age decreased with spousal smoking, such that the wives of men smoking 40 a day were a mean four years younger than wives of men smoking one to 19 a day, probably as a consequence of early death of smoking husbands of similarly aged wives (table 3 on bmj.com).

During the study period mortality from coronary heart disease fell by about 15\% every four years. ${ }^{2}$ The "passive" smokers were therefore predominantly from later cohorts for whom, age for age, mortality from coronary heart disease had fallen significantly in comparison to controls. The same argument applies to never smoking husbands of smoking women who had an average age four to five years lower than controls (table 2 on bmj.com). Adjusting for age alone will not remove this interaction of age and time of observation.

Moreover, the Cox proportional hazard model is critically dependent on assumed proportionality between two survival curves at all points following entry to the study. Mortality from coronary heart disease increases almost exponentially for most of adult life and the mortality curves of risk groups for coronary heart disease differ not only in scale but also in doubling time. As such their survival curves cannot be proportional, yet this was not tested.

The effectiveness of age adjustment in this study is questionable, the year of observation should have been taken into account, and the statistical method is potentially unsound. The biological implausibility of the trend in relative risk may well be an expression of systematic bias in the method.

Eugene Milne deputy medical director

Northumberland and Tyne and Wear Strategic Health Authority, Newcastle General Hospital, Newcastle upon Tyne NE4 6BE eugene.milne@ntwha.nhs.uk

Competing interests: None declared.

1 Enstrom JE, Kabat, GC. Environmental tobacco smoke and Enstrom JE, Kabat, GC. Environmental tobacco smoke and
tobacco related mortality in a prospective study of Califortobacco related mortality in a prospective study of

2 National Center for Health Statistics. Health, United States, 2002. Hyattsville, MD: NCHS, 2002

2002. Hyatsville, MD.NCHS, 2002. 3 Altman DG, Machin D, Bryant TN, Gardner MJ.

\section{Tobacco industry publishes disinformation}

EDITOR-The American Cancer Society does not agree with the conclusions of Enstrom and Kabat in their analysis of environmental tobacco smoke in the cancer prevention study I (CPS-I). ${ }^{1}$ Their study is fatally flawed because of misclassification of exposure. The cancer prevention study was started by the society in 1959 to measure the effects of active smoking, not to collect valid estimates of exposure to environmental tobacco smoke. ${ }^{2}$ No information was obtained on sources of exposure to environmental tobacco smoke other than the smoking status of the spouse. Tobacco smoke was so pervasive in the United States in the 1950 s and 1960 s that virtually everyone was exposed, at home, at work, or in other 
settings. Enstrom and Kabat essentially compare non-smokers, married to a smoking spouse, with non-smokers with other sources of exposure to environmental tobacco smoke. Misclassification of exposure is compounded because no information was collected on the smoking status of the spouse between 1972 and 1999. Nonsmokers whose spouses reported smoking at the start of the study are classified as "exposed" even if the spouse quit, died, or the marriage ended during this interval. This problem is not solved by the 1999 resurvey of survivors, since these represent only $2 \%$ of the original analytic cohort and $5 \%$ of those followed after 1972. Other serious flaws of the Enstrom and Kabat paper are discussed elsewhere. ${ }^{3}$

This is the second attempt by tobacco industry consultants to publish flawed analyses of environmental tobacco smoke using cohort studies from the American Cancer Society. ${ }^{4}$ Sadly, the forum in which such studies are influential is not the scientific world-scientists recognise these studies for what they are-but in communities that are considering clean air laws.

Michael J Thun vice president, epidemiology and surveillance research

American Cancer Society, 1599 Clifton Road,

Atlanta, GA 30329-4251, USA

mthun@cancer.or

Competing interests: None declared.

1 Enstrom JE, Kabat, GC. Environmental tobacco smoke and tobacco related mortality in a prospective study of Califortobacco related mortality in a prospective stud
nians, 1960-98. BMI 2003;326:1057. (17 Mav.)

2 Thun MJ, Henley J, Apicella L. Epidemiologic studies of

Thun MJ, Henley J, Apicella L. Epidemiologic studies of fatal and nonfatal cardiovascular disease and ETS exposure from spousal

3 Thun M. More misleading science from the tobacco industry: delaying clean air laws through disinformation. BMJ try: delaying clean
USA 2003; July:352.

USA 2003:July:352.
LeVois M, Lavard M. Publication bias in the environmental

tobacco smoke/coronary heart disease epidemiologic tobacco smoke/coronary heart disease epid
literature. Reg Toxicol Pharmacol 1995;21:184-91.

\section{Peer review and press release}

EDITOR-The questions raised about the validity of the data reported by Enstrom and Kabat call into question the adequacy of the peer and editorial review of the paper at the $B M J .^{1}$ Apparently no one with special expertise in research on the health effects of passive smoking was involved in the review of this paper. In an area as complex as this-to which massive reports have been devoted $^{2}{ }^{3}$ - one or more persons with epidemiological expertise and an extensive knowledge of the literature on this subject should have been involved in the review of this paper. The obligation to find such a reviewer is heightened when one considers the authors' conflicts of interest and the fact that the paper challenges a huge body of evidence in an area of enormous public health importance.

The $B M J$ 's press release for this paper looks as if it was written by the tobacco industry. It refers to the "already controversial debate on the health impact of passive smoking" and mostly parrots the views of Enstrom and Kabat. In its eight paragraphs, the release allocates three words to the study's limitations. The coup de grâce is that the release does not mention the authors' conflicts of interest. This problem is not unique to the $B M J$. An analysis of press releases issued by seven medical journals (including the $B M J$ ) included 23 studies that were industry funded; only $22 \%$ of the corresponding press releases revealed the source of funding. ${ }^{4}$

\section{Ronald M Davis director}

Center for Health Promotion and Disease

Prevention, Henry Ford Health System, One Ford Place, 5C, Detroit, MI 48202-3450, USA rdavis1@hfhs.org

Competing interests: RMD has been active in tobacco research and tobacco control advocacy since 1979. From 1991 to 1998 , he was editor of the journal Tobacco Control, which is published by the BMJ Publishing Group. He served as North American editor of the BMJ from 1998 to 2001. He has served as an expert witness in many tobacco related lawsuits (including two devoted to passive smoking) but has derived no personal income from such work (fees for his services have been paid to his employer, as he is a salaried employee).

1 Enstrom JE, Kabat, GC. Environmental tobacco smoke and tobacco related mortality in a prospective study of Californians, 1960-98. BMJ 2003:326:1057. (17 May.)

2 US Environent US Esestratory health effects of passive smoking: lung cancer and other disorder. $006 \mathrm{~F}$

3 California Environmental Protection Agency, Office of Envinia Enviontental Protion Agency, Offee of

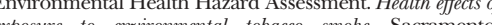
California Environmental Protection Agency, 1997.

4 Woloshin S, Schwartz LM. Press releases: translating Tesearch into news $J 4 M 4$ 2002; $287: 2856-8$.

Agreeing the limits of conflicts of interest

EDITOR-The paper by Enstrom and Kabat ${ }^{1}$ raises the issue of how much conflict of interest can editors reasonably allow before the findings and interpretation of a particular study are rendered unsafe or, at the very least, too uncertain to be a substantive scientific contribution?

If we think that there really is a limit to the degree of conflict that we judge reasonable, as some responses to the Enstrom and Kabat paper seem to imply, then criticism should be directed to the medical community for having such imprecise thinking over conflicts of interest. In pharma sponsored studies, we mostly allow conflicts provided they are reported accurately. We deplore them in tobacco sponsored research. But there are many examples of how both industries have tried to undermine the independence and rigour of research, bias policy makers, and gouge huge profit from disease.

In papers from the pharma industry we publish a statement about the role of the funding source in the design, conduct, analysis, and reporting of the data for all primary research, irrespective of who the sponsor might be (for-profit, not-for-profit etc). No such statement appears in the Enstrom and Kabat paper-would this have helped readers judge the safety and reliability of their research?

Could this paper therefore provide a useful opportunity for us all to clarify what is an acceptable conflict, for readers, researchers, and editors alike, and how that conflict should be reported? Could we agree also about how to handle these matters during prepublication peer review (should the extent of the conflict be a factor, in addition to the science, in deciding acceptance or rejection?)-well before they might confuse an already difficult scientific issue of great public concern?

\section{Richard Horton}

Lancet, London NW1 7BY

richard.horton@lancet.com

Competing interests: None declared.

1 Enstrom JE, Kabat, GC. Environmental tobacco smoke and tobacco related mortality in a prospective study of Californians, 1960-98. BMJ 2003;326:1057. (17 May.)

\section{Background must be examined}

EDITOR-The reviews of the paper by Enstrom and Kabat and the responses to them raise serious concerns about this paper, ${ }^{1}$ strengthened by what has since emerged about one of the author's links to the tobacco industry. As an editor who has been misled by an ostensibly independent scientist later found to be a consultant for the tobacco industry, I am hesitant to criticise others who may find themselves in a potentially similar position as discovering the full story can be lengthy and painful. ${ }^{2}$ One must consider not just the scientific merits of what was published but also the many analyses that could be but were not. One must also scrutinise carefully statements that could be genuine differences of interpretation but may reflect other motives. Especially where passive smoking is concerned, it is essential to examine the background to the study, given the unprecedented resources used by the tobacco industry in their attempts to create uncertainty. ${ }^{3}$

What should happen now? The $B M J$ often responds to controversial papers by simply counting responses for and against This is insufficient, given the many unanswered questions raised by industry documents about the part played by senior tobacco industry executives and their consultants in this paper. ${ }^{4}$ When faced with similar questions about a paper we published on passive smoking we undertook a full investigation, producing evidence that was subsequently used successfully in a legal action in Switzerland. ${ }^{5}$ Without prejudging the outcome, such a review would, prima facie, also seem to be justified in this case.

Competing interests: See reference 4 .

Martin McKee editor in chief, European Journal of Public Health

London School of Hygiene and Tropical Medicine, London WC1E 7HT

martin.mckee@lshtm.acuk

1 Enstrom JE, Kabat, GC. Environmental tobacco smoke and tobacco related mortality in a prospective study of Californians, 1960-98. BMJ 2003:326:1057. (17 May.)

2 McKee M. Smoke and mirrors: clearing the air to expose the tactics of the tobacco industry. Eur I Publ Health 2000;10:161-3.

3 Hong M-K, Bero LA. How the tobacco industry responded to an influential study of the health effects of secondhand moke. BMJ 2002;325:1413-6.

4 McKee M, Diethelm P. More details on competing interests [electronic response to Enstrom and Kabat]. BMJ 2003. 14 Aug 2003)

5 www.prevention.ch/rypresse.htm (accessed 7 Jul 2003). 


\section{Authors' reply}

EDITOR-Owing to the charged atmosphere surrounding the issue of passive smoking, our paper provoked strong reactions on bmj.com. The most disturbing reactions have come from the enforcers of political correctness who pose as disinterested scientists but are willing to use base means to trash a study whose results they dislike. They have no qualms about engaging in personal attacks and unfounded insinuations of dishonesty rather than judging research on its merits. ${ }^{1}$ The resulting confusion has misled many readers and diverted attention from the facts of the study.

Since 15 May Michael Thun of the American Cancer Society has led a campaign to discredit our study, including his letter above. However, almost every sentence in his letter is misleading, and he disregards key information in the full version of our paper. Contrary to the title of his letter, we have presented an accurate analysis of the California cohort of the cancer prevention study I (CPS I), not disinformation, and it comes from the University of California, Los Angeles, and the State University of New York, Stony Brook, not the tobacco industry.

Anyone who reads the full version of the paper and our response to the reviewers of 9 January $^{2}$ will see that in fact we provided detailed evidence that refutes the claim that our study is "fatally flawed because of misclassification of exposure." Contrary to Thun's unsubstantiated assertion that "tobacco smoke was so pervasive in the United States in the 1950 s and 1960s that virtually everyone was exposed, at home, work, or in other settings," the table shows that most female never smokers married to never smokers were not exposed. It also shows that 1959 spousal smoking was strongly related to self reported total exposure to environmental tobacco smoke as of 1999, in spite of the misclassification of exposure that occurred over 40 years.

Thun also attempts to minimise our recontact of survivors in 1999. Instead of the $2 \%$ and $5 \%$ he cites, we obtained 1999 responses from $8.7 \%(3094 / 35561)$ of the subjects alive on 1 January 1960 , from $35.6 \%$ (3094/8693) of the subjects known to be alive as of 31 December 1998, and from about $45 \%$ of the subjects who actually received the questionnaire (see table 1 and text of full paper). In addition, we have shown in tables 2 and 3 that the 1999

Self reported total exposure to environmental tobacco smoke among female never smokers in the California cohort of the cancer prevention study I by smoking status of spouse (taken mainly from tables 4 and 5 of full paper)

History of regular exposure to cigarette smoke from others in work or daily life as of 1999 (\%)

\begin{tabular}{lccrc}
\hline Smoking status of spouse & None & Light & Moderate & Heavy \\
\hline Low exposure: & & & & \\
\hline Married to a never smoker as of 1959 & 61.7 & 24.3 & 10.9 & 3.1 \\
\hline Married to a never smoker as of 1972 & 63.6 & 23.9 & 9.7 & 2.8 \\
\hline Never married to a smoker as of 1999 & 76.7 & 16.1 & 5.3 & 1.9 \\
\hline High exposure: & & & & \\
\hline Married to a smoker of 40+ cigarettes per day as of 1959 & 16.2 & 12.5 & 47.5 & 23.8 \\
\hline Exposed 40+ years to a smoking spouse as of 1999 & 14.1 & 20.5 & 44.3 & 21.1 \\
\hline
\end{tabular}

particular, what are the competing interests of Thun, and where does the American Cancer Society get its funds? Thirdly, and most importantly, the integrity of the underlying data must be thoroughly and fairly investigated. The best way to resolve questions about the validity of research findings is through independent examination of the underlying data, something that is now required in principle by the Data Quality Act for US studies with public policy implications. ${ }^{3}$ Fourthly, journals must be willing to publish and discuss controversial findings, as long as they meet the criteria of good science.

Regarding the comments of the working group of the International Agency for Research on Cancer (IARC), we have not claimed that our study changes the weight of the worldwide evidence on environmental tobacco smoke and lung cancer, but it does change the US evidence. When our results are included, meta-analysis of US results on environmental tobacco smoke and lung cancer among both men and women yields a summary relative risk of about 1.10 for ever/never exposure, which is just on the border of statistical significance. Our results have an even greater impact with regard to environmental tobacco smoke and coronary heart disease, where meta-analysis of US results, which constititute most of the evidence, yields summary relative risks of about 1.05 for current/never and ever/ never exposure. The end of our response to the reviewers summarises the relative risks for environmental tobacco smoke and coronary heart disease by exposure status for all US cohort studies. ${ }^{2}$ Because of our findings, we conclude that "the association between exposure to environmental tobacco smoke and coronary heart disease and lung cancer may be considerably weaker than generally believed." Finally, we do not think the weak association with lung cancer means that environmental tobacco smoke "causes" lung cancer, and we certainly do not think that this issue is "resolved scientifically."

In response to Glaser and Milne, we have used a standard method of analysis for prospective cohort data: Cox proportional hazards regression based on the SAS PHREG program. ${ }^{4}$ All results have been properly adjusted for age at entry, which is by far the strongest risk factor for death. Tables 7 and 8 show that confounding variables such as education have virtually no effect on the relative risks. Too much is being made of statistical fluctuations in tables 2 and 3. For a fair evaluation of our study, it must be put in perspective with all other similar studies, which has not yet been done.

Finally, we too are in favour of the strongest possible protections for nonsmokers. However, the attempt to suppress any divergent results because of their possible effect on public policy can only harm science in the long run. In a rational society, there are ample grounds for regulating involuntary exposure to tobacco smoke without manipulating scientific results. What is most dangerous is the willingness to 
distort the truth to defend one's position, claiming all along that science and righteousness are on one's side.

James E Enstrom researcher

School of Public Health, University of California, Los Angeles, CA 90095-1772, USA jenstrom@ucla.edu

Geoffrey C Kabat associate professor

Department of Preventive Medicine, State

University of New York, Stony Brook, NY 11794-8036, USA

1 Rothman KJ. Conflict of interest: the new McCarthyism in

science. JAMA 1993;269:2782-4.
2 Enstrom JE, Kabat GC. Response to BMJ/2002/011163 Enstrom JE, Kabat GC. Response to BMJ/2002/011163 Manuscript Decision. BMJ 2003. bmj.com/cgi/conte full/326/7398/1057/DCl/7 (accessed 16 Aug 2003). 3 Data Quality Act and OMB Guidelines. Guidelines for ensuring and maximizing the quality, objectivity, utility and integrity of information disseminated by federal agencies; notice; republication. Federal Register 2002;67(36):8451-60. (Friday, $22 \quad$ February.) www.isrl.uiuc.edu/qrd/iq/public/data-qualityguidelines.html (accessed 16 Aug 2003).

So Y. The PHREG procedure. In: SAS/STAT software. SAS technical report P-229. Cary, NC: SAS Institute, 1992 support.sas.com/documentation/onlinedoc/index.htm (accessed 19 Aug 2003)

\section{Summary of rapid responses}

EDITOR-More than 140 readers responded to Enstrom and Kabat's paper and Davey Smith's editorial. ${ }^{12}$ Some of the passion and most of the science is captured in the letters above. What follows is a necessarily brief overview of the remaining ones. The debate started with some orthodox critical comment on the paper: the analysis underestimated the risk to passive smokers, was underpowered, distorted, poorly reported, placed out of context, or just plain wrong. The two main contentions were that a smoking spouse is a poor proxy for passive smoking (because everyone smoked in the $1950 \mathrm{~s}$, so people with non-smoking spouses were still exposed at work), and that many quitters are misclassified as smokers. Both would reduce the difference in mortality between exposed and non-exposed groups. In general, the criticisms were poorly substantiated; only four letters (3\%) referred to actual data in the paper.

The discussions then widened to a number of more or less polite exchanges starting with the evils of the tobacco industry (too numerous to be repeated here), and the competing evils of drug companies that make nicotine replacement therapy. Neither side expressed their own view. Many readers were angry with the $B M J$ for publishing this study. More were angry about the "tabloid" cover on the journal, and the press release, which they said was sensational and misleading. Some thought the $B M J$ 's editors were naive, others thought we were stupid, mad, or irresponsible, and a few suggested darker motives including raising our impact factor by publishing a citable paper. There were calls for a retraction, and one for an internal inquiry. Here are a few typical comments. "It is saddening that a prestigious publication such as BMJ has lowered its publication standards to the point of letting a piece of rubbish occupy its columns and amplifying it with a complaisant editorial." "I cannot believe that a reputable journal such as the British Medical Journal can seriously print such a flawed study except to increase readership and create controversy" and "BMJ, what have you done?" The outrage had three themes: the study was bad for public health and should not have been published. Its conclusions were unreliable because the tobacco industry paid for them. And the methods and analysis were scientifically flawed. How could the paper have got through peer review? You can read our reviewers' comments, and an original, unedited draft of Davey Smith's editorial on bmj.com.

A dozen or so readers defended us. "You are to be congratulated for having the courage to publish research that, while politically incorrect and therefore destined to be excoriated by the anti-smoker lobbyists (many of whom work for anti-smoking organizations and therefore have obvious conflicts of interest even if they refuse to cite them) meets these criteria. Take solace that you are only being bashed verbally-Galileo paid a greater price for promulgation of his research that challenged the worldview of the catholic majority," wrote the director of facilities at an American university. She had no competing interests to declare.

Neither did most other respondents, despite some giving tell tale addresses such as Smoke Free Educational Services Inc, Smoke Free Pennsylvania, Adults Saving Kids, and Forces International (an advocacy group for smokers). One reader thought the $B M J$ was being ironic, asking them for a competing interest statement, and a few others simply wrote "I enjoy smoking" or "I quit smoking." Enstrom and Kabat wrote over 200 words explaining their funding and competing interests, but it wasn't enough. Both were accused of "swimming with sharks" and asked to clarify their dealings with the tobacco industry. One of them, Geoffrey Kabat, did so, adding, "To imply that skepticism about the 'weak association' of passive smoking with heart disease and lung cancer is due to influence from the tobacco industry is simply wrong-headed. There is legitimate debate about the effects of passive smoking on heart disease and lung cancer. The evidence is not as uniform or as strong as the activists and scientists with extra-scientific agendas make out." James Enstrom has clarified his dealings with the tobacco industry in BMJ/2003/ 084269. Richard Horton, the editor of the Lancet, concluded that the entire medical community is guilty of muddled thinking on conflicting interests.

Many letters were highly charged and hostile. "It is astounding how much of the criticism springs from Ad Hominem argument rather than from scientific criticism of the study itself," wrote a "private citizen" from Philadelphia PA. "As a publisher of the leading Austrian medical online news service I feel quite embarrassed following the debate on this article. Many postings look more like a witch hunt than a scientific debate," wrote another. It got bitter, and at times personal. A great read for anyone who enjoys a scrap. Disappointing for readers looking for a dispassionate appraisal of Enstrom and Kabat's study and its implications.

Alison Tonks associate editor $B M J$

1 Enstrom J, Kabat G. Environmental tobacco smoke and tobacco related mortality in a prospective study of Californians, 1960-98. BMJ 2003;326:1057-61. (17 Mav.)

2 Davey Smith G. Effect of passive smoking on health. $B M J$ 2003;326:1048-9. (17 May.)

\section{Comment from the editor}

EDITOR-I can't respond to all the points raised in this debate, and I thought I would simply share some reflections.

Firstly, we've considered again whether we should we have a blanket policy of refusing to publish research funded by the tobacco industry. We've twice considered this question in the $B M J$ and twice decided against. The $B M J$ is passionately antitobacco, but we are also passionately prodebate and proscience. A ban would be antiscience.

Secondly, we are not in the "truth" business. Scientific truths are all provisional. Most of science falls away as new paradigms emerge. This doesn't mean that we are in the "lies" business, but we are in the "debate" business. We judged this paper ${ }^{1}$ to be a useful contribution to an important debate. We may be wrong, as we are with many papers. That's science.

Thirdly, with research papers we first ask if we are interested in the question. We must be interested in whether passive smoking kills, and the question has not been definitively answered. It's a hard question, and our methods are inadequate.

We then peer review the study, but we are well aware of the extreme deficiencies of peer review. Of course the study we published has flaws-all papers do-but it also has considerable strengths: long follow up, large sample size, and more complete follow up than many such studies. It's too easy to dismiss studies like this as "fatally flawed," with the implication that the study means nothing

Fourthly, I found it disturbing that so many people and organisations referred to the flaws in the study without specifying what they were. Indeed, this debate was much more remarkable for its passion than its precision.

Richard Smith editor

$B M J$

Competing interests: RS is the editor of the $B M J$ and accountable for all that it publishes. 1 Enstrom JE, Kabat, GC. Environmental tobacco smoke and
tobacco related mortality in a prospective study of Californians, 1960-98. BMJ 2003;326:1057. (17 May.)

\section{bmj.com}

Letters appearing here are an edited selection of rapid responses originally posted on bmj.com

We ask for all letters to the editor to be submitted as rapid responses via bmj.com

For advice see: bmj.com/rapidresponses 